\title{
Dietary TAG Source and Level Affect Performance and Lipase Expression in Larval Sea Bass (Dicentrarchus labrax)
}

\author{
S. Morais ${ }^{a, *}$, C. Cahu ${ }^{b}$, J.L. Zambonino-Infante ${ }^{b}$, J. Robin ${ }^{b}$, I. Rønnestad ${ }^{c}$, \\ M.T. Dinis ${ }^{a}$, and L.E.C. Conceição ${ }^{a}$
}

\author{
${ }^{a}$ Centro de Ciências do Mar (CCMAR), Universidade do Algarve, Campus de Gambelas, 8005-139 \\ Faro, Portugal \\ ${ }^{\mathrm{b}}$ Institut Français de Recherche pour l'Exploration de la Mer (IFREMER), 29280 Plouzané, France \\ ${ }^{\mathrm{c}}$ Department of Zoology, University of Bergen, N-5007 Bergen, Norway.
}

*: Corresponding author : Centro de Ciências do Mar (CCMAR), Universidade do Algarve, Campus de Gambelas, 8000-117 Faro, Portugal. E-mail: smorais@ualg.pt

\begin{abstract}
:
The influence of dietary TAG source (fish oil, triolein, and coconut oil) and level ( 7.5 and $15 \%$ of the diet) on growth, lipase activity, and mRNA level was studied in sea bass larvae, from mouth opening until day 24 and from day 37 to 52 . Fish oil and triolein induced better growth in both experiments, this being significant at a higher dietary level. Coconut oil significantly decreased growth at the higher level, possibly as the result of an excessive supply of medium-chain TAG. Growth was not related to lipase specific activity, suggesting a production in excess to dietary needs. Body lipid content was positively related to dietary lipid level and was affected by lipid quality. In addition, larval FA composition generally reflected that of the diet. The source of dietary lipid, but not the quantity, was shown to affect lipase activity significantly. Coconut oil diets induced the highest lipase activity, whereas the effect of fish oil was age dependent-it was similar to coconut oil at day 24 but induced the lowest lipase activity in 52-d-old larvae. The differential lipase response was probably caused by differences in the FA composition of the diet, related to the specificity of lipase toward FA differing in chain length and degree of saturation. No significant differences were found in lipase/glyceraldehyde3-phosphate dehydrogenase mRNA, which suggests the existence of a posttranscriptional regulation mechanism
\end{abstract}


In spite of the considerable progress achieved in marine larval nutrition in the last decades, larval rearing of many commercially important marine species is still far from optimal. Marine larval rearing is mostly dependent on the production of live feeds and on the manipulation of their nutritional profile, although relatively good results have been achieved recently with the exclusive use of inert diets (1). Some of the earlier studies conducted with fish larvae associated the simple morphological structure of the digestive system with a low production of proteolytic enzymes and explained the failure of rearing fish larvae with inert diets by a lower digestion efficiency (e.g. 2,3). Nonetheless, in general, measurements of the digestive enzyme content of larvae reveal significant levels of pancreatic and intestinal enzymes (4-6). Therefore, the problems encountered in rearing marine larvae on inert diets may be more a question of an inadequacy of the diet composition and physical properties in relation to the digestive characteristics of the larval stages leading to an inadequate stimulation of enzyme release, rather than a low digestive capacity $(5,7)$.

Relatively few studies have examined the influence of dietary composition on the regulation of gastrointestinal tract function and development in fish, even though diet quality appears to have a direct effect on the onset of the maturation processes of the digestive tract $(5,8,9)$. Studies looking at the quantitative lipid requirements of marine fish larvae have described a stimulation of the lipolytic activities of pancreatic lipase and phospholipase A2 by an increase in their substrate level in the diet (8). However, the quality of the dietary lipid source is also an important parameter and has been little investigated. Triacylglycerols (TAG) are generally the quantitatively most important lipid class in fish diets and their physical nature, namely the carbon chain length and the degree of saturation of their fatty acids (FA), has been shown to affect digestion and absorption (10-13). Having this in mind, the present study was conducted in order to study the effect of dietary TAG quality and quantity in larval development and lipase expression in European sea bass (Dicentrarchus labrax L.).

\section{MATERIALS AND METHODS}

Rearing and experimental diets. Eggs of European sea bass (Dicentrarchus labrax L.) were obtained from the marine hatchery of Aquanord (Gravelines, France). Two experiments were conducted at Ifremer - Station de Brest, using the same batch of eggs (January 2003), and in both larvae were fed only formulated diets from mouth opening (day 5). The first experiment was carried out from day 5 until day 24. Rearing of the experimental animals was conducted in 18 black cylindrical-conical tanks (35 L). Initial stocking density in the first experiment was 80 larvae/L. The tanks were supplied with running filtered and thermoregulated sea water (sand filter, tungsten heater, degassing column, UV lamp and, finally, $10 \mu \mathrm{m}$ cartridge filter). The temperature was regulated at $14^{\circ} \mathrm{C}$ for the 5 day old larvae and gradually increased during 4 days, being finally stabilised at $18-19^{\circ} \mathrm{C}$. Salinity was lowered from $35-38 \mathrm{ppm}$ to $25 \mathrm{ppm}$ at day 5. Light intensity was progressively increased until reaching full light at day 16, with a maximum intensity of $9 \mathrm{~W} / \mathrm{m}^{2}$ at the water surface. The oxygen level was maintained above 6 $\mathrm{mg} / \mathrm{L}$ by setting the water exchange to $30 \%$ per hour $(0.18 \mathrm{~L} / \mathrm{min})$. The second experiment lasted from day 37 (average wet weight $=35.4 \mathrm{mg}$ ) to day 52. During the first 36 days larvae were reared in the same conditions as in the first experiment, except for the diet fed (Gemma Micro 150, followed by Gemma Micro 300, Trouw France, Fontaine-les-vervins). Larvae were stocked in the experimental tanks on day 36, at a density of 19 larvae/L.

Six microparticulate diets were formulated to contain 3 different neutral lipid sources, differing on the carbon chain length and degree of saturation of their FA - fish oil (cod liver oil), purified (>99\%) triolein (a TAG composed of a glycerol backbone and three 18:1n-9) and coconut oil - at 2 inclusion levels (7.5 and 15\%), and were designated as F7.5, T7.5, C7.5, 
F15, T15 and C15 (Table 1). The two lipid levels were achieved by balancing the level of carbohydrate (starch), while protein was maintained constant. The dietary ingredients were mechanically mixed with $10 \%$ water using a Hobart mixer (Bernstein Schaltsysteme, Germany), pelleted and dried at $60^{\circ} \mathrm{C}$ during $30 \mathrm{~min}$. The pellets were ground and sieved to obtain particles of size $<400 \mu \mathrm{m}$. Fish were continuously fed in excess (2g/day/tank on days 6-10, 4g/day/tank until day 15, 6g/day/tank until day 25 and 8g/day/tank from day 26 onwards) with belt feeders, during $18 \mathrm{~h}$ per day. Food ingestion was monitored by observing the larval digestive tract under a binocular microscope and diet acceptability was found to be good from start feeding. Each diet was tested in triplicate randomized tanks.

Sampling. All sampling procedures were conducted in the morning, after cleaning the tanks and before food distribution, to assure that larvae had an empty digestive tract. In order to monitor growth, 15 larvae were removed weekly from each tank in the first experiment (days 11, 18 and 24) and at the start and end of the second experiment, rinsed in fresh water and immediately weighted. Survival was only determined at the end of the second experiment by individually counting the larvae (individuals removed during sampling were added to the number of surviving animals). For the biochemical assays larvae were collected straight into ice, without rinsing in fresh water. Collection of larvae for lipase activity assays was conducted on day 18 ( $\mathrm{n}=100$ larvae per tank) and day 24 (n variable - all surviving larvae) in the first experiment, and at the end of the second experiment (day 52, $\mathrm{n}=12$ larvae per tank). Larvae were immediately stored at $-80^{\circ} \mathrm{C}$, pending dissection of the pancreatic segment and assays. In the first experiment whole larvae were assayed. Larvae were also collected for mRNA quantification but, in this case, total RNA extraction (of whole larvae in the first experiment and of dissected pancreatic segments in the second) was carried out immediately. This was performed on day 16 (n variable - app. 250-300 mg wet weight) in the first experiment and on day 51 ( $\mathrm{n}=5$ larvae per tank) in the second experiment. Dissections were performed on a glass maintained on ice; a segment containing the pancreatic section was cut from just behind the head to the middle of the digestive tract. Samples for biochemical composition and FA analysis were also collected at the start (day 36; $\mathrm{n}=100$ larvae per triplicate) and at the end (day 52; $\mathrm{n}=60$ larvae per tank) of the second experiment. Larvae were immediately stored at $-20^{\circ} \mathrm{C}$ until analysis.

Proximate composition and fatty acid analysis. The diets were ground and whole larvae (day 36 and 52) were ground frozen, freeze-dried and homogenised before analysis. Duplicate aliquots were analysed for dry matter after desiccation in an oven (DM; $105^{\circ} \mathrm{C}, 24 \mathrm{~h}$ ) and ash (incineration at $550^{\circ} \mathrm{C}, 12 \mathrm{~h}$ ), following standard laboratory procedures (14). Total protein content was determined according to Dumas (15) (N x 6.25) in a Nitrogen Analyser NA2000 (Fison instrument), using DL-methionine as an internal standard. Total lipid was extracted using the method of Folch et al. (16), with chloroform being replaced by dichloromethane. Total FA were saponified by a $2 \mathrm{M} \mathrm{KOH}$-methanol solution and then esterified in a $0.7 \mathrm{M}$ HCl-methanol solution. Fatty acid methyl esters (FAME) were separated by gas chromatography, in an Auto-system Perkin-Elmer with a flame ionisation detector, BPX 70 capillary column ( $25 \mathrm{~m}$ x $0.22 \mathrm{~mm}$ i.d. x $0.25 \mu \mathrm{m}$ film thickness), split-splitless injector, with helium as carrier gas. The injector and detector temperatures were 220 and $260^{\circ} \mathrm{C}$, respectively. Initial temperature of the oven was $50^{\circ} \mathrm{C}$, increasing to $180^{\circ} \mathrm{C}$ by increments of $15^{\circ} \mathrm{C} / \mathrm{min}$, maintained for $5 \mathrm{~min}$, and finally increased to $220^{\circ} \mathrm{C}$ by increments of $3^{\circ} \mathrm{C} / \mathrm{min}$. Data acquisition and handling were carried out by connecting the GC to a PE Nelson computer. The individual FAME were identified by comparing the retention time of standard methyl esters mixtures - 68A (Interchim), ME64 (Larodan), AOCS n5 (Sigma) - and the results of individual FA composition are expressed as percent of total identified FAME. Proximate composition of the diets and larvae is shown in Table 1 and 3, respectively, while the FA composition of the experimental diets and larvae can be seen in Table 2. 
Lipase enzymatic determination. Pancreatic segments were homogenized in $1.5 \mathrm{~mL}$ (first experiment) or $3 \mathrm{~mL}$ (second experiment) of cold $\left(4^{\circ} \mathrm{C}\right)$ distilled water. Lipase activity was assayed according to a spectrophotometric method slightly modified from Iijima et al. (17), using as substrate p-nitrophenyl myristate (Sigma) dissolved in dimethylsulfoxid (DMSO, Merck-Schuchardt) $65.8 \mathrm{mM}$, as this was found to aid substrate solubilisation. Protein was determined according to Bradford (18) and enzymatic activity is expressed as specific activity, $\mathrm{U} / \mathrm{mg}$ protein $\left(\mathrm{U}=\mu\right.$ mole of substrate hydrolyzed per minute at $30^{\circ} \mathrm{C}$ ).

$m R N A$ quantification. Lipase mRNA was quantified through reverse transcriptase polymerase chain reaction analysis. Total RNA extraction was performed using TRIzol ${ }^{\circledR}$ (Gibco BRL). After RNA quantification by spectrophotometry reading, $5.5 \mu \mathrm{g}$ of total RNA were collected and reverse-transcripted to cDNA, using the Ready To Go T-Primed First Strand Kit (Pharmacia Biotech, Uppsala, Sweden). The quantification of mRNA coding for lipase was normalised relative to the mRNA specific housekeeping gene glyceraldehyde-3phosphate dehydrogenase (GAPDH), i.e., results are presented as lipase mRNA/GAPDH mRNA. GAPDH has been chosen as the housekeeping gene since its expression did not significantly vary during sea bass larval development (1). Polymerase chain reaction (PCR) of a $50 \mu \mathrm{L}$ solution containing $1-3 \mu \mathrm{L}$ of cDNA, $5 \mu \mathrm{L}$ of a $10 \mathrm{X}$ buffer solution (Qbiogene), $2 \mu \mathrm{L}$ of $20 \mathrm{mM}$ dNTPs (Eurogentec), $0.5 \mu \mathrm{L}$ of $5 \mathrm{U} / \mu \mathrm{L}$ Taq polymerase (Qbiogene), 50 picomoles of each primer and sterilised distilled water to complete the $50 \mu \mathrm{L}$ volume was carried out in a thermocycler (Robocycler ${ }^{\circledR}$ Gradient 96, Stratagene). PCR conditions were as follows: initial denaturation at $94^{\circ} \mathrm{C}$ for 30 seconds followed by 30 cycles including denaturation at $94^{\circ} \mathrm{C}$ for 1 minute, annealing at specific temperatures $\left(50^{\circ} \mathrm{C}\right.$ for lipase and $56^{\circ} \mathrm{C}$ for GAPDH) for 1.5 minutes and 2 minute elongation at $72^{\circ} \mathrm{C}$. A final extension cycle was performed at $72^{\circ} \mathrm{C}$ for 7 minutes. Primer sequences were: 5' - TGT GGC TTC AAC AGC - 3' and 5' - CGC TCC AAG RCT GTA - 3' (Cybergene) for lipase; and 5' - CAC CAC GCT CAC CAT CGC - 3' and 5' - CAT CTT GGG GAA CAT GTG - 3' (Eurogentec) for GAPDH. Quantification of RT-PCR products coding for lipase and GAPDH was achieved by applying $10 \mu \mathrm{l}$ of each PCR product on a $1.2 \%$ agarose $(0.8 \%$ agarose plus $0.4 \%$ low melting temperature agarose) ethidium bromide $(1 \mathrm{mg} / \mathrm{L})$ gel, followed by image capture in a multi-imager (Bio-Rad MultiAnalyst $^{\mathrm{TM}}$ ) and quantification using the software Image Master ${ }^{\mathrm{TM}}$ TotalLab (Amersham Pharmacia Biotech, Uppsala, Sweden). The limits of the exponential phase and the beginning of the saturation phase of the amplification reaction were determined for each gene (by a calibration curve plotting the product of a 30 cycle PCR against the known start concentration of the cDNA) to ensure the linear relationship between start RNA and final RT-PCR product.

Statistical analyses. Results are given as mean values \pm standard deviations (SD) of triplicate or duplicate (diet biochemical composition) samples. Data from larval weight, survival rate, body composition, lipase activity and mRNA levels were compared by a twoway analysis of variance (ANOVA) followed by the Tukey HSD multiple range test when significant differences were found at the $\mathrm{P}<0.05$ level, using the software Statistica 6 (StatSoft Inc.). The two analysed factors were "lipid quantity" (2 levels - 7.5 and 15\%) and "lipid quality" (3 levels - fish oil, triolein and coconut oil). The assumption of homogeneity of variance was previously checked using the Bartlett's test and survival rates were $\arcsin \left(\mathrm{x}^{1 / 2}\right)$ transformed (19). In the cases where a significant interaction was found between the two factors, a one way ANOVA was performed to analyse the results.

\section{RESULTS}

Larval performance. No significant differences in survival were found in the second experiment (Table 3). Assuming that sampled larvae would not result in further mortality 
(sampling times were concentrated at the end of the experiment), survival varied between 86 and 93\%. In the first experiment, due to reduced growth, all surviving larvae were required for lipase assays and survival was not quantified, as it would extend sampling time and potentially lead to enzyme degradation. In terms of growth, statistically significant differences were found in the first experiment, on all sampling dates (Fig. 1), and at the end of the second experiment (Fig. 2). A significant effect of "lipid quantity" was found at all sampling dates, except for day 11 of the first experiment, and the factor "lipid quality" had a significant effect at all times. However, a significant interaction was found between the two analysed factors on day 17 and 24 of the first experiment and in the second experiment, most probably as the result of the effect of coconut oil on larval growth. In both experiments, an increase in the dietary lipid level resulted in a significantly higher growth of larvae fed the fish oil and triolein diets, whereas for coconut oil a higher dietary level was responsible for a significantly lower growth. In terms of "lipid quality", fish oil induced a significantly higher growth at day 11 of the first experiment, while no significant differences were found between triolein and coconut oil at this time. At day 17 and 24 of the first experiment, significant differences were found between all lipid sources, with triolein and coconut oil inducing the significantly highest and lowest growth, respectively. At the end of the second experiment, the diet containing fish oil at a higher inclusion level gave a significantly higher growth (although not statistically different from diet T15).

Larval biochemical composition. No significant differences were found in the moisture and ash content of the larvae at the end of the second experiment (Table 3). As for the total lipid and FA content, significant differences were found for both factors. A higher dietary lipid level gave a significantly higher larval lipid and FA content. There was also a significant effect of lipid quality, with the triolein diet giving a significantly higher lipid and FA content, followed by the fish oil diet, while the coconut oil diet gave a significantly lower body incorporation of lipid and FA. For protein content, an inverse trend was noted but it was not statistically significant. The results of the seabream FA analysis (Table 2) revealed an increase in the relative amount of the FA predominant in the diet, over the course of the experiment. The fish oil diets gave the highest larval polyunsaturated fatty acid (PUFA) content, mainly as a result of the high HUFA (highly unsaturated fatty acids; $\geq 20$ carbon atoms, $\geq 4$ double bonds) level. The larvae fed these diets presented intermediate levels of saturated fatty acids (SFA) and monounsaturated fatty acids (MUFA), as a result of the high levels of 14:0 and 16:0 and of most MUFA, except 18:1n-9. The triolein diets gave the highest MUFA (mainly 18:1n-9) level and the lowest total SFA and PUFA content. The larvae fed coconut oil diets had the highest level of SFA, particularly of 10:0, 12:0 and 14:0, being 10:0 and 12:0 detected only in these larvae. In addition, larvae fed the C7.5 and C15 diets obtained relative levels of PUFA and HUFA comparable to the fish oil diets, particularly F7.5, and similar to that measured at the start of the experiment. When the dietary oil inclusion level was increased the general effect on the larvae was an increase in the relative level of the predominant FA, accompanied by a concomitant decrease in the remaining FA.

Lipase specific activity and mRNA level. In the first experiment no significant differences were found in lipase specific activity on day 18 (Fig. 3A), while some differences were found on day 24 for both lipid quantity and quality (Fig. 3B). At this age, a lower lipid inclusion level was responsible for a significantly higher lipase activity, independently of lipid source. The analysis of the factor "lipid quality" revealed that triolein was responsible for a significantly lower lipase activity, while no significant differences were found between fish oil and coconut oil. At the end of the second experiment only the factor "lipid quality" was found to give significant differences in lipase specific activity, with all dietary lipid sources being statistically different from each other (Fig. 4A). Diets containing coconut oil induced a significantly higher lipase activity at day 52, and those having fish oil were responsible for the 
lowest lipase activity. No significant changes occurred when the lipid inclusion level was increased from $7.5 \%$ to $15 \%$. No significant differences were found in the lipase/GAPDH mRNA values, both during the first (Fig. 3C) and second (Fig. 4B) experiments.

\section{DISCUSSION}

The long term adaptation of larval fish lipolytic enzymes to the qualitative lipid content of the diet has not, to our knowledge, been addressed so far. Hence, the objectives of this study were to investigate not only the effect of TAG quantity but also of its quality on performance, body composition and lipase activity and mRNA levels in seabass larvae.

Larval performance in relation to lipid source. Fish oil is generally considered as reference oil for fish nutrition. The use of triolein as the neutral lipid source in the diet of larval seabass produced growth results close to those obtained with fish oil, particularly at the high inclusion level. Larval growth obtained with coconut oil at a low dietary inclusion level was comparable to other TAG sources, whereas at a higher level it had a growth depressing effect. Coconut oil is one of the few natural sources of medium chain triacylglycerols (MCT), which are composed of SFA with a carbon chain length between 6 and 12 carbon atoms. Medium chain fatty acids (MCFA) are water soluble, which facilitates their emulsification, hydrolysis and uptake by the intestinal mucosa. They are not re-esterified by the enterocyte, being transported directly to the liver as free FA (bound to albumin) in the portal circulation $(11,20)$. Coconut oil has been previously used with good growth results in larval carp $(21,22)$ and in juvenile red drum (23). In the present study, however, the C15 diet contained a higher amount of coconut oil than has been tested before. Fontagné et al. $(21,22)$ found that coconut oil can be fed to common carp larvae without adverse effects up to $10 \%$ in the diet. However, the MCFA caprylic acid (8:0), one of the components of the coconut oil diet, gave reduced growth in common carp at levels above $2 \%$ of the diet (or around $10 \%$ of total FA), while lower levels were well utilised (22). In our study, the C15 diet included 2.5\% caprylic acid. Craig and Gatlin (23) also noted that juvenile red drum were generally not able to utilize 8:0 efficiently, although at a low level weight gain was not significantly different from a control diet. The negative effects of MCFA have been explained by the high ketogenic properties of these FA, particularly of 8:0 (21,23). The intensive $\beta$-oxidation of MCFA leads to the production of ketone bodies which may be well or poorly utilised as an energy source depending on the amount of MCT used, type of MCFA, quantities of other dietary ingredients (e.g. carbohydrates), species-specific differences, size (i.e., "dilution" of dietary FA by endogenous FA), stage of development and energetic needs $(21,22,24,25)$. In the present study, total FA levels of 2.5\% of caprylic acid (8:0), 4.0\% of capric acid (10:0) and 36.8\% of lauric acid (12:0) were associated with a significantly decreased growth of seabass larvae, indicating that they may be at least as vulnerable to dietary MCT as carp or red drum. However, the experimental design of the present study does not allow clarifying whether the growth depression was a consequence of an excessive dietary supply of coconut oil or of the higher relative level of a specific MCFA. In addition, the higher lipid level in the C15 diet was achieved through the elimination of dietary starch and this might have exacerbated the metabolic effects of MCFA (24). Younger larvae appeared more sensitive to coconut oil, given that in 52 day old fish C15 resulted in a significantly lower growth than diets F15 and T15 but, contrary to the first experiment, was not significantly different from the diets F7.5, T7.5 and C7.5. Finally, it should be noted that the lower growth obtained with the C15 diet was not associated to a lower survival of 52 day old seabass, as obtained with other fish larvae fed high levels of MCFA (21-23). However, just as with the detrimental effects on growth, mortality has been related to high levels of 8:0 in the diet and not to dietary coconut oil. 
Larval performance in relation to lipid level. It has been suggested that young seabass larvae do not tolerate high dietary neutral lipid levels (1). The generally poor growth obtained in the first experiment also indicate this but growth in the second experiment starting at 37 days appeared not to be affected by the inclusion of neutral lipids, even at higher levels. In general, higher growth was achieved when a larger amount of total energy was supplied in the lipid form, as previously observed $(8,9)$. This indicates a potential effect of lipid in sparing protein for growth, as also found in juvenile fish $(26,27)$. On the other hand, a higher total energy intake might also explain the results if larval fish do not regulate food intake according to dietary energy content, as previously described for juvenile and adult fish $(26,27)$. Coconut oil was an exception in terms of potentially having a protein sparing effect, even though MCFA have been shown to enhance nutrient absorption and decrease amino acid oxidation (28). However, alterations of FA metabolism, as discussed above, might have obscured any potential protein sparing effect of coconut oil.

Effect of dietary TAG level and source on body composition. Increasing the lipid level in the diets resulted in an overall rise in the seabass body lipid content. In addition, differences in adiposity were also found depending on the source of lipid. The triolein diets were responsible for the highest body lipid accumulation whereas a reduced lipid deposition was noted in larvae fed the coconut oil diets. The same has been found by researchers testing the beneficial effects of dietary MCT in improving carcass quality in several fish species $(21,28-$ 30). The FA composition of seabass larvae generally reflected that of their diet, as is commonly found in fish $(21,29)$. The fish oil diets which had the highest PUFA levels gave the highest PUFA and HUFA content in the larvae. Larvae fed the coconut oil diets had unusually high amounts of 12:0 and 14:0 in their composition, as well as 10:0, which was not detected in any of the other larvae (just as 12:0). Therefore, as previously observed in larval sea bass, carp and juvenile red drum $(21,25,29)$, MCFA were incorporated into body lipid stores, although at a low level. Despite the relatively low level of PUFA in the coconut oil diets, compared to the fish oil diets, the larvae fed these diets had a similar PUFA and HUFA content, and the relative content of HUFA did not change substantially from the start of the experiment. This might be explained by the presence of MCFA in the coconut oil diets, which are preferentially catabolised for energy production (24), potentially "sparing" the essential PUFA. Furthermore, a likely consequence of the lower total lipid content of larvae fed coconut oil diets is a higher proportion of polar lipids, which are richer in PUFA, particularly 22:6n-3 (DHA) and 20:5n-3 (EPA). Finally, the triolein diets were seen to give very high levels of 18:1n-9 in the larvae, which directly reflects the composition of the diet. This was not previously seen in larval seabass fed a diet containing triolein, where a low deposition of 18:1n-9 in body lipids was explained by its degradation for energetic purposes (25).

Effect of dietary TAG source on lipase activity. In the present study, the source of dietary TAG significantly affected lipase enzymatic activity, most likely as a consequence of their substantially different FA composition. The FA specificity of lipolytic enzymes has been relatively well studied and the effects of FA on the activity of pancreatic lipase are related to both the acyl chain length and degree of saturation $(11,31)$. In fish, the digestibility of FA has been shown to decrease with increasing chain length and to increase with unsaturation $(10,13)$. Fish lipases have a preference for PUFA as substrates, followed by MUFA, with SFA being more resistant to lipolysis $(12,13,17,32,33)$. Therefore, fish oils commonly have a good digestibility, while vegetable oils containing MUFA and particularly SFA show a more reduced digestibility. In general, when coconut oil was used as the lipid source, seabass had a higher lipase specific activity (although not significantly different from fish oil in the first experiment). The present results suggest therefore that lipolytic activity might be stimulated by the MCFA and/or SFA (mainly 12:0 and 14:0) present in coconut oil. More than half of the coconut oil SFA are of the MCFA-type, which have the advantage of being rapidly and 
completely digested, even in the absence of bile salts, requiring minimal pancreatic lipase activity (24). In fact, TAG containing FA $<12$ carbons can even be absorbed directly, without hydrolysis (24). MCT replacing fish oil in the diets of adult Atlantic salmon were seen to improve lipid digestibility by 3\% and to increase pancreatic proteolytic activity of the chyme; lipolytic activity was also slightly enhanced, although not significantly (28). Saraux et al. (34) noted that in rat lipase activity was maximally stimulated by coconut oil, but not significantly different from lard (99\% C>12:0). In addition, the digestibility of coconut oil has been analysed in Artic charr and 12:0 was found to be a good substrate for intestinal lipase, the lipolysis of 14:0 being intermediate (13).

A surprising finding was the marked decrease in enzymatic activity caused by the fish oil diet in the second experiment, particularly at the higher inclusion level. This difference in lipase activity (nearly 4 times lower in the group fed the F15 diet, compared to the group fed C7.5) is unlikely to be caused by the difference in weight among the fish groups, which was about $17 \%$. The fish oil diet is characterized by a high level of PUFA, for which lipase has maximal specificity (13). Nevertheless, it contained also the highest levels of several long chain MUFA and of the SFA 16:0, which have been reported to be resistant to hydrolysis and absorption (12,32). Austreng et al. (10) noted that in spite of the high digestibility of long chain (C20-22) FA characteristic of marine oils, the C16-18 FA also present in these oils were less well digested than those in soybean oil. On the other hand, the physiological digestive response to the fish oil-based diet was age-dependent, as the same diet gave relatively high levels of lipase specific activity (comparable to coconut oil) in the first experiment.

The chemical nature of the FA, particularly their carbon chain length, has been shown to influence the release of cholecystokinin (CCK) and secretin, which are hormones implicated in the stimulation of pancreatic enzyme secretion $(31,35,36)$. However, results obtained with different species reveal that MCT or long chain TAG may cause distinct effects in humans and other mammals (37-39). Additionally, ketones have also been implicated as mediators of pancreatic adaptation to dietary lipids, as blood ketone levels are strongly correlated with pancreatic lipase content (31). This may partially explain the results obtained with the coconut oil diets, which are more ketogenic that the other diets tested. Except for preliminary work on the CCK-mediated stimulation of pancreatic secretion by proteins and amino acids $(40,41)$, the adaptation of pancreatic secretion to dietary components in fish remains completely unknown. However, having in mind the present results, it may be hypothesized that if a CCKmediated mechanism exists, CCK release is probably also sensitive to the chemical nature of the FA. In addition, it can be hypothesized that the long term feeding of seabass larvae with more digestible diets containing long chain FA, such as those using fish oil, cause an adaptative response leading to a lower secretion of pancreatic lipolytic enzymes. On the contrary, in a dietary regime containing less digestible oils, an elevated lipolytic activity would be maintained. However, there are many confounding effects in the present study's diets and definite conclusions can not be drawn at this time.

Effect of dietary TAG level on lipase activity. A stimulating effect of dietary lipid content on lipolytic enzymes has been reported both in mammals $(31,36,42)$ and in fish, including seabass $(8,43)$. In rats, lipase activity was correlated with lipid intake but the range of adaptative variation was narrow (app. twofold) (34). In the present study, the increase of dietary lipid level was generally not found to affect lipase specific activity and, on day 24, a lower lipid level even appeared to induce a higher lipase activity. However, differences in the lipid level (17\% vs. $24 \%$ total lipid) were not as marked as in the previous work conducted with seabass, in which significant differences were only found between the dietary groups containing $10 \%$ lipids and $>20 \%$ lipids (8). Moreover, the low lipid level (17\%) was close to the plateau of $20 \%$ dietary lipids reported by Zambonino Infante and Cahu (8), over which there was no further stimulation of lipase activity. Additionally, the pancreatic enzyme 
response to intestinal stimulants has been related to the load (amount per unit of time) rather than to concentration. Thus, it has been suggested that the intestinal receptors for these intraluminal stimulants require only a very low concentration for activation, the length of the intestine exposed to these products being the main determinant of the total pancreatic secretory response (35). If this is the case in marine fish larvae, the ingestion rate of the diet may also play a major role in determining lipase activity. In accordance with this theory, Hoehne-Reitan et al. (44) showed that the bile salt-dependent lipase content of turbot larvae appeared to be a function of the ingestion rate, while the lipid level of the prey had no effect.

Lipase activity and growth. Growth was not related to lipase enzymatic activity, indicating that these two factors might be independent. In fact, a large excess of pancreatic lipase secretion in relation to dietary needs has been reported in humans (31). If this is also the case in young fish, a diminished lipase specific activity might not necessarily affect growth. Results obtained so far by studying lipid digestion and transport in fish larvae seem to indicate that the transport of lipid from the enterocytes into the peripheral tissues may be more of a problem in small larvae than lipid digestion (45). In larval red drum fed a microparticulate diet, live prey or both, enzyme activity was not the limiting factor for growth (46). Furthermore, measurements of bile salt-dependent lipase in turbot larvae suggest that it is present in more than enough quantity for the lipid digestion of all ingested prey (47). The physiological significance of pancreatic adaptation to the diet remains therefore puzzling.

Regulation of lipase activity. Both transcriptional and translational regulation has been detected in rat pancreatic lipase in response to high fat diets $(31,42)$. In the present study no significant differences were found in the lipase/GAPDH mRNA values, confirming previous hypothesis of an involvement of a post-transcriptional or translational mechanism, with a hormonal modulation (eventually through CCK or secretin action) of the efficiency of mRNA translation $(1,8)$. However, it was additionally postulated that the regulation of lipase activity occurs also at the transcriptional level in seabass larvae $(1,8)$. No evidence of this was found in the present study although the high variability associated with the determination of mRNA synthesis may have obscured potential dietary effects.

In conclusion, the data presented here suggests the existence of a regulatory mechanism of neutral lipolytic enzyme secretion and activity according to the dietary FA composition operating in marine fish larvae. However, an understanding of the underlying mechanisms controlling such an adaptation as well as of the physiological importance of such a regulation is still scarce.

\section{ACKNOWLEDGMENTS}

Sofia Morais acknowledges support from the "Fundação para a Ciência e a Tecnologia", Portugal (grant SFRH/BD/4902/2001) and from the European Commission (ASEFAF, EEC HPRI - CT - 2001 - 0014; IFREMER ref. No. 01/1214121/TF). The authors would like to express their gratitude to Patrick Quazuguel for assistance during diet formulation, Magali Hervy for helping with larval rearing and sampling, Marie Le Gall for technical assistance in the laboratory and Hervé Le Delliou for diet and larval composition analysis.

\section{REFERENCES}

1. Cahu, C.L., Zambonino Infante, J.L., and Barbosa, V. (2003) Effect of Dietary Phospholipid Level and Phospholipid: Neutral Lipid Value on the Development of Sea Bass (Dicentrarchus labrax) Larvae Fed a Compound Diet, Brit. J. Nutr. 90, 21-28. 
2. Lauff, M., and Hofer, R. (1984) Proteolytic Enzymes in Fish Development and the Importance of Dietary Enzymes, Aquaculture 37, 335-346.

3. Person Le Ruyet, J., Alexandre, J.C., Thébaud, L., and Mugnier, C. (1993) Marine Fish Larvae Feeding: Formulated Diets or Live Prey?, J. World Aquacult. Soc. 24, 211-224.

4. Pedersen, B.H., Nilssen, E.M., and Hjelmeland, K. (1987) Variations in the Content of Trypsin and Trypsinogen in Larval Herring (Clupea harengus) Digesting Copepod Nauplii, Mar. Biol. 94, 171-181.

5. Cahu, C.L., Zambonino Infante, J.L., Le Gall, M.M., and Quazuguel, P. (1995) Early Weaning of Seabass: Are Digestive Enzymes Limiting?, in LARVI '95 - Fish \& Shellfish Larviculture Symposium (Lavens, P., Jaspers, E., and Roelants, I., eds.), European Aquaculture Society Special Publication No. 24, pp. 268-271,Gent, Belgium.

6. Ribeiro, L., Zambonino Infante, J.L., Cahu, C., and Dinis, M.T. (1999) Development of Digestive Enzymes in Larvae of Solea senegalensis, Kaup 1858, Aquaculture 179, 465-473.

7. Hjelmeland, K., Pedersen, B.H., and Nilssen, E.M. (1988) Trypsin Content in Intestines of Herring Larvae, Clupea harengus, Ingesting Inert Polystyrene Spheres or Live Crustacea Prey, Mar. Biol. 98: 331-335.

8. Zambonino Infante, J.L., and Cahu, C.L. (1999) High Dietary Lipid Levels Enhance Digestive Tract Maturation and Improve Dicentrarchus labrax Larval Development, J. Nutr. 129, 1195-1200.

9. Buchet, V., Zambonino Infante, J.L., and Cahu, C.L (2000) Effect of Lipid Level in a Compound Diet on the Development of Red Drum (Sciaenops ocellatus) larvae, Aquaculture 184, 339-347.

10. Austreng, E., Skrede, A., and Eldegard, Å. (1979) Effect of Dietary Fat Source on the Digestibility of Fat and Fatty Acids in Rainbow Trout and Mink, Acta Agric. Scand. 29, 119-126.

11. Linscheer, W.G., and Vergroesen, A.J. (1994) Lipids, in Modern Nutrition in Health and Disease (Shils, M.E., Olson, J.A., and Shike, M. eds), pp. 47-88, Williams \& Wilkins, U.S.A..

12. Koven, W.M., Henderson, R.J., and Sargent, J.R. (1994) Lipid Digestion in Turbot (Scophthalmus maximus). I: Lipid Class and Fatty Acid Composition of Digesta from Different Segments of the Digestive Tract, Fish Physiol. Biochem. 13, 69-79.

13. Olsen, R.E., Henderson, R.J., and Ringø, E. (1998) The Digestion and Selective Absorption of Dietary Fatty Acids in Arctic Charr, Salvelinus alpinus, Aquacult. Nutr. 4, 13-21.

14. AOAC (Association of Official Analytical Chemists) (1984) Official Methods of Analysis, 12th edn., Association of Official Analytical Chemists, Washington, DC.

15. Dumas, J.-B. (1831) Ann. Chim. Phys. 47, 198.

16. Folch, J., Lees, M., and Sloane-Stanley, G.H. (1957) A Simple Method for the Isolation and Purification of Total Lipids from Animal Tissues, J. Biol. Chem. 226, 497-509.

17. Iijima, N., Tanaka, S., and Ota, Y. (1998) Purification and Characterization of Bile Salt-Activated Lipase from the Hepatopancreas of Red Sea Bream, Pagrus major, Fish Physiol. Biochem. 18, 59-69.

18. Bradford, M.M. (1976) A Rapid and Sensitive Method for the Quantitation of Microgram Quantities of Protein Utilizing the Principle of Protein-Dye Binding, Anal. Biochem. 72, 248-254.

19. Zar J.H. (1996) Biostatistical Analysis, Prentice Hall International, NJ, USA.

20. Jenkins, D.J.A., Wolever, T.M.S., and Jenkins, A.L. (1994) Diet Factors Affecting Nutrient Absorption and Metabolism, in Modern Nutrition in Health and Disease 
(Shils, M.E., Olson, J.A., and Shike, M. eds), pp. 583-602, Williams \& Wilkins, U.S.A..

21. Fontagné, S., Pruszynski, T, Corraze, G., and Bergot, P. (1999) Effect of Coconut Oil and Tricaprylin vs. Triolein on Survival, Growth and Fatty Acid Composition of Common Carp (Cyprinus carpio L.) Larvae, Aquaculture 179, 241-251.

22. Fontagné, S., Corraze, G., and Bergot, P. (2000) Response of Common Carp (Cyprinus carpio) Larvae to Different Dietary Levels and Forms of Supply of Medium-Chain Fatty Acids, Aquat. Liv. Resour. 13, 429-437.

23. Craig, S.R., and Gatlin, D.M. (1995) Coconut Oil and Beef Tallow, but not Tricaprylin, Can Replace Menhaden Oil in the Diet of Red Drum (Sciaenops ocellatus) Without Adversely Affecting Growth or Fatty Acid Composition, J. Nutr. 125, 3041-3048.

24. Bach, A.C., and Babayan, V.K. (1982) Medium-Chain Triglycerides: An Update, Am. J. Clin. Nutr. 36, 950-962.

25. Fontagné, S., Robin, J., Corraze, G., and Bergot, P. (2000) Growth and Survival of European Sea Bass (Dicentrarchus labrax) Larvae Fed From First Feeding on Compound Diets Containing Medium-Chain Triacylglycerols, Aquaculture 190, 261271.

26. Boujard, T., and Médale, F. (1994) Regulation of Voluntary Feed Intake in Juvenile Rainbow Trout Fed by Hand or by Self Feeders With Diets Containing Two Different Protein/Energy Ratios, Aquat. Liv. Resour. 7, 211-215.

27. Sæther, B.-S., and Jobling, M. (2001) Fat Content in Turbot Feed: Influence on Feed Intake, Growth and Body Composition, Aquacult. Res. 32, 451-458.

28. Nordrum, S., Krogdahl, Å., Røsjø, C., Olli, J.J., and Holm, H. (2000) Effects of Methionine, Cysteine and Medium Chain Triglycerides on Nutrient Digestibility, Absorption of Amino Acids Along the Intestinal Tract and Nutrient Retention in Atlantic Salmon (Salmo salar L.) Under Pair-Feeding Regime, Aquaculture 186, 341360.

29. Davis, D.A., Lazo, J.P., and Arnold, C.R. (1999) Response of Juvenile Red Drum (Sciaenops ocellatus) to Practical Diets Supplemented With Medium Chain Triglycerides, Fish Physiol. Biochem. 21, 235-247.

30. Røsjø, C., Nordrum, S., Olli, J.J., Krogdahl, Å, Ruyter, B., and Holm, H. (2000) Lipid Digestibility and Metabolism in Atlantic Salmon (Salmo salar) Fed Medium-Chain Triglycerides, Aquaculture 190, 65-76.

31. Brannon, P.M. (1990) Adaptation of the Exocrine Pancreas to Diet, Ann. Rev. Nutr. 10, 85-105.

32. Lie, Ø., and Lambertsen, G. (1985) Digestive Lipolytic Enzymes in Cod (Gadus morhua): Fatty Acid Specificity, Comp. Biochem. Physiol. 80B, 447-450.

33. Gjellesvik, D.R., 1991. Fatty Acid Specificity of Bile Salt-Dependent Lipase: Enzyme Recognition and Super-Substrate Effects, Biochim. Biophys. Acta 1086, 167-172.

34. Saraux, B., Girard-Globa, A., Ouagued, M., and Vacher, D. (1982) Response of the Exocrine Pancreas to Quantitative and Qualitative Variations in Dietary Lipids, Am. J. Physiol. 243, G10-G15.

35. Singer, M.V. (1987) Pancreatic Secretory Response to Intestinal Stimulants: A Review, Scand. J. Gastroent. 22 (suppl 139), 1-13.

36. Spannagel, A.W., Nakano, I., Tawil, T., Chey, W.Y., Liddle, R.A., and Green, G.M. (1996) Adaptation to Fat Markedly Increases Pancreatic Secretory Response to Intraduodenal Fat in Rats, Am. J. Physiol. 33, G128-G135.

37. Hopman, W.P.M., Jansen, J.B.M.J., Rosenbusch, G., and Lamers, C.B.H.W. (1984) Effect of Equimolar Amounts of Long-Chain Triglycerides and Medium-Chain 
Triglycerides on Plasma Cholecystokinin and Gallbladder Contraction, Am. J. Clin. Nutr. 39, 356-359.

38. Matzinger, D., Degen, L., Drewe, J., Meuli, J., Duebendorfer, R., Ruckstuhl, N., D’Amato, M., Rovati, L., and Beglinger, C. (2000) The Role of Long Chain Fatty Acids in Regulating Food Intake and Cholecystokinin Release in Humans, Gut 46, 688-693.

39. Douglas, B.R., Jansen, J.B.M.J., De Jong, A.J.L., and Lamers, C.B.H.W. (1990) Effect of Various Triglycerides on Plasma Cholecystokinin Levels in Rats, J. Nutr. 120, 686690.

40. Koven, W., Rojas-Garcia, C.R., Finn, R.N., Tandler, A., and Rønnestad, I. (2002) Stimulatory Effect of Ingested Protein and/or Free Amino Acids on the Secretion of the Gastro-Endocrine Hormone Cholecystokinin and on Tryptic Activity, in EarlyFeeding Herring Larvae, Clupea harengus, Mar. Biol. 140, 1241-1247.

41. Rojas-García, C.R., and Rønnestad, I. (2002) Cholecystokinin and Tryptic Activity in the Gut and Body of Developing Atlantic Halibut (Hippoglossus hippoglossus): Evidence for Participation in the Regulation of Protein Digestion, J. Fish Biol. 61, 973-986.

42. Wicker, C., and Puigserver, A. (1989) Changes in mRNA Levels of Rat Pancreatic Lipase in the Early Days of Consumption of a High-Lipid Diet, Eur. J. Biochem. 180, 563-567.

43. Borlongan, I.G. (1990) Studies on the Digestive Lipases of Milkfish, Chanos chanos, Aquaculture 89, 315-325.

44. Hoehne-Reitan, K., Kjørsvik, E., and Reitan, K.I. (2001) Bile Salt-Dependent Lipase in Larval Turbot, as Influenced by Density and Lipid Content of Fed Prey, J. Fish Biol. $58,746-754$.

45. Izquierdo, M.S., Socorro, J., Arantzamendi, L., and Hernández-Cruz (2000) Recent Advances in Lipid Nutrition in Fish Larvae, Fish Physiol. Biochem. 22, 97-107.

46. Lazo, J.P., Holt, G.J., and Arnold, C.R. (2000) Ontogeny of Pancreatic Enzymes in Larval Red Drum Sciaenops ocellatus, Aquacult. Nutr. 6, 183-192.

47. Hoehne-Reitan, K., Kjørsvik, E., and Gjellesvik, D.R. (2001) Development of Bile Salt-Dependent Lipase in Larval Turbot, J. Fish Biol. 58, 737-745. 
TABLE 1

Experimental Diet Formulation and Proximate Composition ${ }^{a}$.

\begin{tabular}{|c|c|c|c|c|c|c|}
\hline & F7.5 & T7.5 & C7.5 & F15 & T15 & C15 \\
\hline \multicolumn{7}{|l|}{ Diet Ingredients (g/kg dry diet) } \\
\hline \multicolumn{7}{|l|}{ Constant ingredients } \\
\hline Fish meal $^{1}$ & 540 & 540 & 540 & 540 & 540 & 540 \\
\hline Hydrolyzed fish meal $^{2}$ & 130 & 130 & 130 & 130 & 130 & 130 \\
\hline Soybean lecithin ${ }^{3}$ & 50 & 50 & 50 & 50 & 50 & 50 \\
\hline Vitamin mixture ${ }^{4}$ & 80 & 80 & 80 & 80 & 80 & 80 \\
\hline Mineral mixture $^{5}$ & 40 & 40 & 40 & 40 & 40 & 40 \\
\hline Betaine $^{6}$ & 10 & 10 & 10 & 10 & 10 & 10 \\
\hline \multicolumn{7}{|l|}{ Variable ingredients } \\
\hline Fish oil (cod liver oil) ${ }^{7}$ & 75 & 0 & 0 & 150 & 0 & 0 \\
\hline Triolein (purified) ${ }^{8}$ & 0 & 75 & 0 & 0 & 150 & 0 \\
\hline Coconut oil $^{9}$ & 0 & 0 & 75 & 0 & 0 & 150 \\
\hline $\operatorname{Starch}^{10}$ & 75 & 75 & 75 & 0 & 0 & 0 \\
\hline \multicolumn{7}{|l|}{ Proximate Composition } \\
\hline Dry matter (DM, \%) & $97.8 \pm 0.0$ & $97.6 \pm 0.0$ & $97.6 \pm 0.1$ & $97.1 \pm 0.0$ & $97.4 \pm 0.2$ & $97.5 \pm 0.0$ \\
\hline Protein (N x 6.25) (\% DM) & $58.3 \pm 0.2$ & $58.7 \pm 0.4$ & $58.8 \pm 0.2$ & $58.5 \pm 0.0$ & $57.7 \pm 0.0$ & $58.4 \pm 0.4$ \\
\hline Lipid (\% DM) & $17.0 \pm 0.6$ & $16.9 \pm 0.7$ & $16.0 \pm 0.1$ & $24.2 \pm 0.5$ & $24.4 \pm 0.6$ & $23.9 \pm 0.7$ \\
\hline Ash (\% DM) & $12.0 \pm 0.1$ & $12.0 \pm 0.0$ & $12.2 \pm 0.1$ & $12.0 \pm 0.0$ & $13.5 \pm 0.1$ & $12.0 \pm 0.0$ \\
\hline Protein energy / Lipid energy ${ }^{11}$ & 1.5 & 1.5 & 1.6 & 1.1 & 1.0 & 1.1 \\
\hline
\end{tabular}

${ }^{a}$ Values are Means \pm SD $(n=2)$.

${ }^{1}$ La Lorientaise, Sopropêche, Lorient, France.

${ }^{2}$ CPSP 90, Sopropêche, Boulogne sur mer, France.

${ }^{3}$ Louis François, St. Maur, France.

${ }^{4}$ Composé Vitaminique 762, INRA, Jouy-en-Josas, France. Per kg of vitamin mix: retinyl acetate - 1g; cholecalciferol - 2.5mg; all-rac- $\alpha$-tocopherol acetate - 10g; menadione - 1g; thiamin - 1g; riboflavine - 0.4g; D- calcium pantothenate - 2g; pyridoxine $\mathrm{HCl}$ - 0.3g; cyanocobalamin - 1g; niacin - 1g; choline chloride - 200g; ascorbic acid - 20g; folic acid $0.1 \mathrm{~g}$; biotine - 1g; meso-inositol - 30g.

${ }^{5}$ Composé Minéral 763, INRA, Jouy-en-Josas, France. Per kg of mineral mix: KCl - 90g; KI 40mg; CaHPO4.2H2O - 500g; NaCl - 40g; CuSO4.5H2O - 3g; ZnSO4.7H2O - 4g; CoSO4.7H2O - 20mg; FeSO4.7H2O - 20g; MnSO4.H2O - 3g; CaCO3 - 215g; MgSO4.7H2O - 124g; NaF - 1g.

${ }^{6}$ Betaine (min. 99\%) Sigma, France.

${ }^{7}$ La Lorientaise, Sopropêche, Lorient, France (14:0 - 6.3\%, 15:0 - 1.0\%, 16:0 - 14.0\%, 16:1 6.0\%, 18:0 - 1.7\%, 18:1 - 16.7\%, 18:2 - 2.0.\%, 18:3 - 1.2\%, 18:4 - 3.0\%, 20:1 - 11.3\%, 20:5 9.8\%, 22:1- 12.4\%, 22:5 - 0.6\%, 22:6 - 8.0\%).

${ }^{8}$ VWR Prolabo,Fontenay-sous-Bois, France. $\mathrm{C}_{57} \mathrm{H}_{104} \mathrm{O}_{6} ;$ d. $0.91 ; \mathrm{M}=885.46 \mathrm{~g} / \mathrm{mol}$.

${ }^{9}$ Coconut Oil Supreme ${ }^{\mathrm{TM}}$, Mid-American Marketing Corp., Eaton, USA (8:0 - 8.86\%, 10:0 6.17\%, 12:0 - 48.83\%, 14:0 - 19.97\%, 16:0 - 7.84\%, 18:0 - 3.06\%, 18:2 - 0.76\%, 18:1 4.44\%, 20:0 - 0.05\%).

${ }^{10}$ Pregelatinised Starch, Pregeflo ${ }^{\circledR}$ P100, Roquette, Lille, France.

${ }^{11}$ Calculated as: lipid x $37.7 \mathrm{~J} \mathrm{~kg}^{-1}$; protein x $16.7 \mathrm{~J} \mathrm{~kg}^{-1}$. 
TABLE 2

Fatty Acid Composition of the Experimental Diets and of the Larvae at the Start (day

36) and at the End of the Second Experiment (day 52) ${ }^{a}$.

\begin{tabular}{|c|c|c|c|c|c|c|c|c|c|c|c|c|c|}
\hline \multirow{2}{*}{$\begin{array}{l}\text { Fatty } \\
\text { acids } \\
(\%)\end{array}$} & \multicolumn{6}{|c|}{ Experimental diets } & \multicolumn{7}{|c|}{ Larvae } \\
\hline & F7.5 & T7.5 & C7.5 & F15 & T15 & C15 & Start & F7.5 & T7.5 & $\mathbf{C 7 . 5}$ & F15 & T15 & C15 \\
\hline $8: 0$ & 0.0 & 0.0 & 1.9 & 0.0 & 0.0 & 2.5 & 0.0 & 0.0 & 0.0 & 0.0 & 0.0 & 0.0 & 0.0 \\
\hline 10:0 & 0.0 & 0.0 & 3.0 & 0.0 & 0.0 & 4.0 & 0.0 & 0.0 & 0.0 & 0.3 & 0.0 & 0.0 & 0.5 \\
\hline $12: 0$ & 0.2 & 0.0 & 26.9 & 0.1 & 0.0 & 36.8 & 0.0 & 0.0 & 0.0 & 7.1 & 0.0 & 0.0 & 11.5 \\
\hline $14: 0$ & 5.5 & 1.8 & 12.4 & 5.8 & 1.2 & 15.3 & 1.5 & 3.4 & 1.2 & 7.2 & 3.2 & 0.9 & 9.5 \\
\hline $16: 0$ & 16.4 & 10.2 & 12.6 & 16.1 & 7.9 & 11.0 & 17.5 & 18.2 & 11.9 & 17.2 & 16.0 & 9.3 & 16.3 \\
\hline $18: 0$ & 3.3 & 3.7 & 3.3 & 3.3 & 3.6 & 3.0 & 5.4 & 5.2 & 4.9 & 5.7 & 4.5 & 4.6 & 5.6 \\
\hline $20: 0$ & 0.2 & 0.2 & 0.1 & 0.3 & 0.3 & 0.1 & 0.2 & 0.2 & 0.2 & 0.2 & 0.2 & 0.2 & 0.2 \\
\hline $22: 0$ & 0.2 & 0.6 & 0.1 & 0.2 & 0.7 & 0.1 & 0.1 & 0.0 & 0.2 & 0.0 & 0.0 & 0.3 & 0.0 \\
\hline $14: 1$ & 0.3 & 0.2 & 0.2 & 0.3 & 0.1 & 0.0 & 0.2 & 0.1 & 0.0 & 0.0 & 0.2 & 0.0 & 0.0 \\
\hline $16: 1 n-7$ & 5.3 & 1.8 & 1.8 & 5.9 & 1.3 & 1.2 & 2.5 & 4.7 & 1.8 & 2.3 & 5.2 & 1.3 & 2.1 \\
\hline 18:1n-7 & 1.0 & 0.0 & 0.0 & 1.1 & 0.0 & 0.0 & 2.9 & 3.2 & 2.0 & 1.9 & 3.3 & 1.8 & 1.6 \\
\hline $20: 1 n-7$ & 0.3 & 0.0 & 0.1 & 0.3 & 0.0 & 0.0 & 0.2 & 0.4 & 0.0 & 0.0 & 0.4 & 0.0 & 0.0 \\
\hline $18: 1 n-9$ & 10.8 & 45.2 & 7.0 & 11.7 & 56.5 & 6.3 & 12.0 & 12.3 & 37.8 & 10.6 & 12.3 & 48.5 & 10.9 \\
\hline $20: 1 n-9$ & 5.6 & 2.9 & 2.5 & 5.9 & 2.3 & 1.9 & 4.5 & 5.4 & 3.7 & 3.6 & 5.5 & 3.6 & 3.0 \\
\hline $22: 1 n-9$ & 0.7 & 0.3 & 0.3 & 0.8 & 0.3 & 0.2 & 0.5 & 0.5 & 0.3 & 0.3 & 0.5 & 0.2 & 0.2 \\
\hline $24: 1 n-9$ & 0.6 & 0.3 & 0.3 & 0.6 & 0.2 & 0.2 & 0.2 & 0.3 & 0.3 & 0.3 & 0.2 & 0.2 & 0.2 \\
\hline $18: 1 n-11$ & 2.8 & 1.6 & 1.1 & 3.0 & 1.4 & 0.8 & 0.5 & 1.3 & 0.0 & 1.0 & 1.3 & 0.0 & 0.5 \\
\hline 20:1n-11 & 0.8 & 0.3 & 0.3 & 0.8 & 0.0 & 0.0 & 0.7 & 1.0 & 0.4 & 0.7 & 1.0 & 0.0 & 0.6 \\
\hline 22:1n-11 & 6.4 & 3.2 & 3.0 & 6.6 & 2.1 & 1.8 & 2.9 & 3.9 & 2.1 & 2.2 & 3.7 & 1.4 & 1.5 \\
\hline $18: 2 n-6$ & 12.4 & 15.4 & 11.0 & 9.1 & 13.6 & 7.3 & 23.2 & 12.1 & 14.6 & 13.5 & 9.6 & 13.8 & 12.2 \\
\hline $18: 3 n-6$ & 0.2 & 0.1 & 0.1 & 0.2 & 0.1 & 0.0 & 0.1 & 0.2 & 0.2 & 0.2 & 0.2 & 0.2 & 0.2 \\
\hline $20: 2 n-6$ & 0.3 & 0.1 & 0.1 & 0.3 & 0.1 & 0.0 & 1.4 & 1.0 & 0.8 & 1.6 & 0.9 & 0.6 & 1.5 \\
\hline $20: 3 n-6$ & 0.2 & 0.0 & 0.0 & 0.2 & 0.0 & 0.0 & 0.0 & 0.1 & 0.1 & 0.1 & 0.2 & 0.0 & 0.1 \\
\hline $20: 4 n-6$ & 0.6 & 0.3 & 0.3 & 0.6 & 0.2 & 0.2 & 0.8 & 1.0 & 0.7 & 0.8 & 0.9 & 0.4 & 0.8 \\
\hline $22: 5 n-6$ & 0.3 & 0.4 & 0.1 & 0.3 & 0.3 & 0.1 & 0.1 & 0.3 & 0.2 & 0.2 & 0.3 & 0.2 & 0.3 \\
\hline $18: 3 n-3$ & 2.4 & 1.8 & 1.9 & 2.0 & 1.2 & 1.2 & 2.9 & 1.8 & 1.6 & 2.0 & 1.7 & 1.2 & 1.8 \\
\hline $18: 4 n-3$ & 2.3 & 1.0 & 1.0 & 2.3 & 0.7 & 0.7 & 0.7 & 1.3 & 0.6 & 1.0 & 1.5 & 0.4 & 0.9 \\
\hline $20: 3 n-3$ & 0.1 & 0.0 & 0.0 & 0.1 & 0.0 & 0.0 & 0.1 & 0.0 & 0.0 & 0.1 & 0.0 & 0.0 & 0.0 \\
\hline $20: 4 n-3$ & 0.8 & 0.2 & 0.2 & 1.0 & 0.2 & 0.1 & 0.3 & 0.6 & 0.3 & 0.4 & 0.9 & 0.2 & 0.3 \\
\hline $20: 5 n-3$ & 8.5 & 3.0 & 3.1 & 9.0 & 2.1 & 1.9 & 6.1 & 7.4 & 4.3 & 6.1 & 9.4 & 3.3 & 5.6 \\
\hline $22: 5 n-3$ & 1.5 & 0.4 & 0.3 & 1.9 & 0.2 & 0.2 & 0.8 & 1.5 & 0.6 & 0.8 & 2.0 & 0.5 & 0.7 \\
\hline $22: 6 n-3$ & 10.1 & 4.9 & 4.9 & 10.3 & 3.3 & 2.9 & 11.9 & 12.7 & 9.4 & 12.5 & 14.6 & 6.9 & 11.3 \\
\hline$\sum \mathrm{SFA}^{1}$ & 25.7 & 16.5 & 60.3 & 25.7 & 13.7 & 72.9 & 24.6 & 27.0 & 18.4 & 37.6 & 23.9 & 15.3 & 43.5 \\
\hline$\sum$ MUFA $^{2}$ & 34.6 & 55.9 & 16.8 & 37.1 & 64.2 & 12.4 & 27.1 & 32.9 & 48.4 & 23.0 & 33.7 & 57.0 & 20.7 \\
\hline$\sum$ PUFA $^{3}$ & 39.7 & 27.6 & 22.9 & 37.3 & 22.1 & 14.7 & 48.3 & 40.1 & 33.3 & 39.4 & 42.3 & 27.8 & 35.8 \\
\hline$\sum$ HUFA $^{4}$ & 21.0 & 8.5 & 8.5 & 22.2 & 5.8 & 5.1 & 19.0 & 22.2 & 14.5 & 19.8 & 27.0 & 10.8 & 18.0 \\
\hline
\end{tabular}

${ }^{a}$ Values are Means (diets, $n=2$; larvae, $n=3$, except F15, where $n=1$ ); SD was bellow 0.004 in diets and 0.05 in larvae.

${ }^{1}$ SFA, saturated fatty acids; ${ }^{2}$ MUFA, monounsaturated fatty acids; ${ }^{3}$ PUFA, polyunsaturated fatty acids; ${ }^{4}$ HUFA, highly unsaturated fatty acids. 
TABLE 3

Survival and Biochemical Composition of the Larvae at the Start (day 36) and at the End of the Second Experiment (day 52) ${ }^{a}$.

\begin{tabular}{llllllll}
\hline & Start & F7.5 & T7.5 & C7.5 & F15 & T15 & C15 \\
\hline Survival (\%) & & $89.1 \pm 3.1$ & $85.7 \pm 3.0$ & $88.4 \pm 2.9$ & $92.8 \pm 3.1$ & $90.4 \pm 3.0$ & $87.9 \pm 2.4$ \\
& & & & & & & \\
Biochemical Composition & & & & & & & \\
Moisture (\%) & $91.6 \pm 1.2$ & $87.7 \pm 0.6$ & $86.2 \pm 1.4$ & $86.4 \pm 1.4$ & $87.0 \pm 1.3$ & $86.2 \pm 1.6$ & $88.7 \pm 1.8$ \\
Ash (\% DM) & $22.0 \pm 0.0$ & $16.3 \pm 0.9$ & $15.1 \pm 0.3$ & $16.2 \pm 0.6$ & $14.3 \pm 0.8$ & $15.0 \pm 2.3$ & $17.7 \pm 2.2$ \\
Lipid (\% DM) & $20.3 \pm 1.3$ & $19.9 \pm 1.1^{\mathrm{ab}}$ & $20.9 \pm 0.2^{\mathrm{b}}$ & $17.2 \pm 1.0^{\mathrm{c}}$ & $24.6 \pm 0.5^{\mathrm{d}}$ & $26.5 \pm 0.5^{\mathrm{d}}$ & $18.7 \pm 0.2^{\mathrm{ac}}$ \\
Total Fatty acids (\% DM) & $14.6 \pm 0.1$ & $14.6 \pm 1.1^{\mathrm{ab}}$ & $16.6 \pm 0.2^{\mathrm{ab}}$ & $13.2 \pm 0.9^{\mathrm{a}}$ & $17.2 \pm 2.7^{\mathrm{b}}$ & $21.7 \pm 1.0^{\mathrm{c}}$ & $13.9 \pm 0.3^{\mathrm{ab}}$ \\
Protein (N x 6.25) (\% DM) & $61.1 \pm 2.4$ & $62.2 \pm 0.9$ & $64.0 \pm 3.3$ & $64.6 \pm 1.2$ & $59.1 \pm 0.3$ & $58.3 \pm 0.6$ & $62.6 \pm 0.4$ \\
\hline
\end{tabular}

${ }^{a}$ Values are means \pm S.D. $(\mathrm{n}=3)$. Values within the same line with different superscript letters are significantly different ( $\mathrm{P}<0.05$, one way ANOVA), but only results at the end of the experiment (day 52) were compared. 


\section{FIGURE LEGENDS}

FIG. 1. Wet weight (mg) on day 11, 17 and 24 of the first experiment. Data are means \pm SD $(n=3)$. Columns with different letters on each day are significantly different $(P<0.05$; one-way ANOVA).

FIG. 2. Wet weight (mg) at the end of the second experiment (day 52). Data are means \pm SD $(n=3)$. Columns with different letters are significantly different $(\mathrm{P}<0.05$; one-way ANOVA).

FIG. 3. Lipase specific activity (U/mg protein) and lipase/GAPDH mRNA values assayed in the first experiment. (A) - day 18; (B) - day 24; (C) - day 16. Data are means \pm SD ( $n=3)$. Columns with different symbols ("lipid quantity" factor) or different letters ("lipid quality" factor) are significantly different $(\mathrm{P}<0.05$; two-way ANOVA).

FIG. 4. Lipase specific activity (U/mg protein) and lipase/GAPDH mRNA values assayed at the end of the second experiment. (A) - day 52; (B) - day 51. Data are means \pm SD ( $n=3)$. Columns with different letters ("lipid quality" factor) are significantly different $(\mathrm{P}<0.05$; twoway ANOVA). 


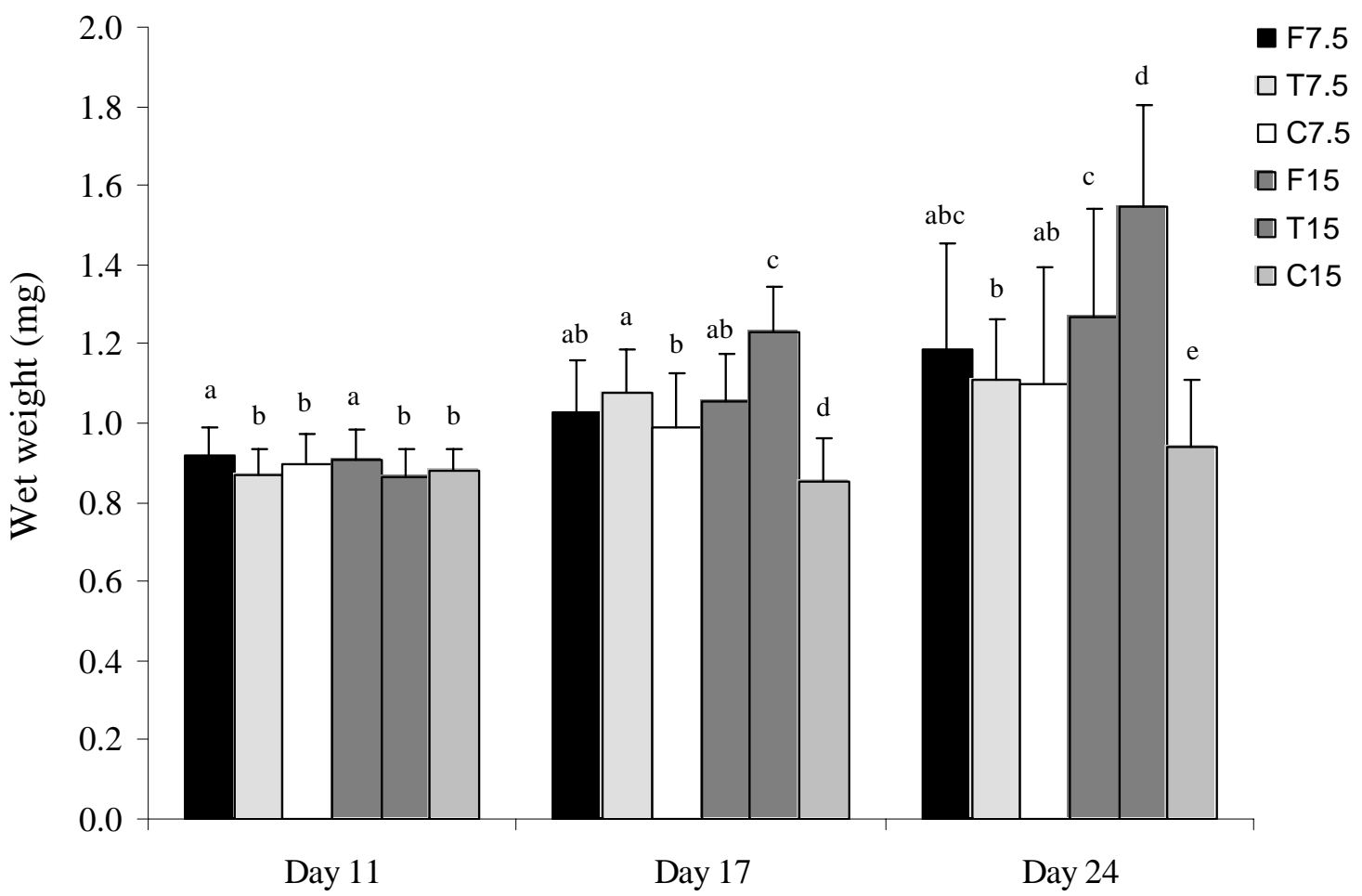

FIG. 1 


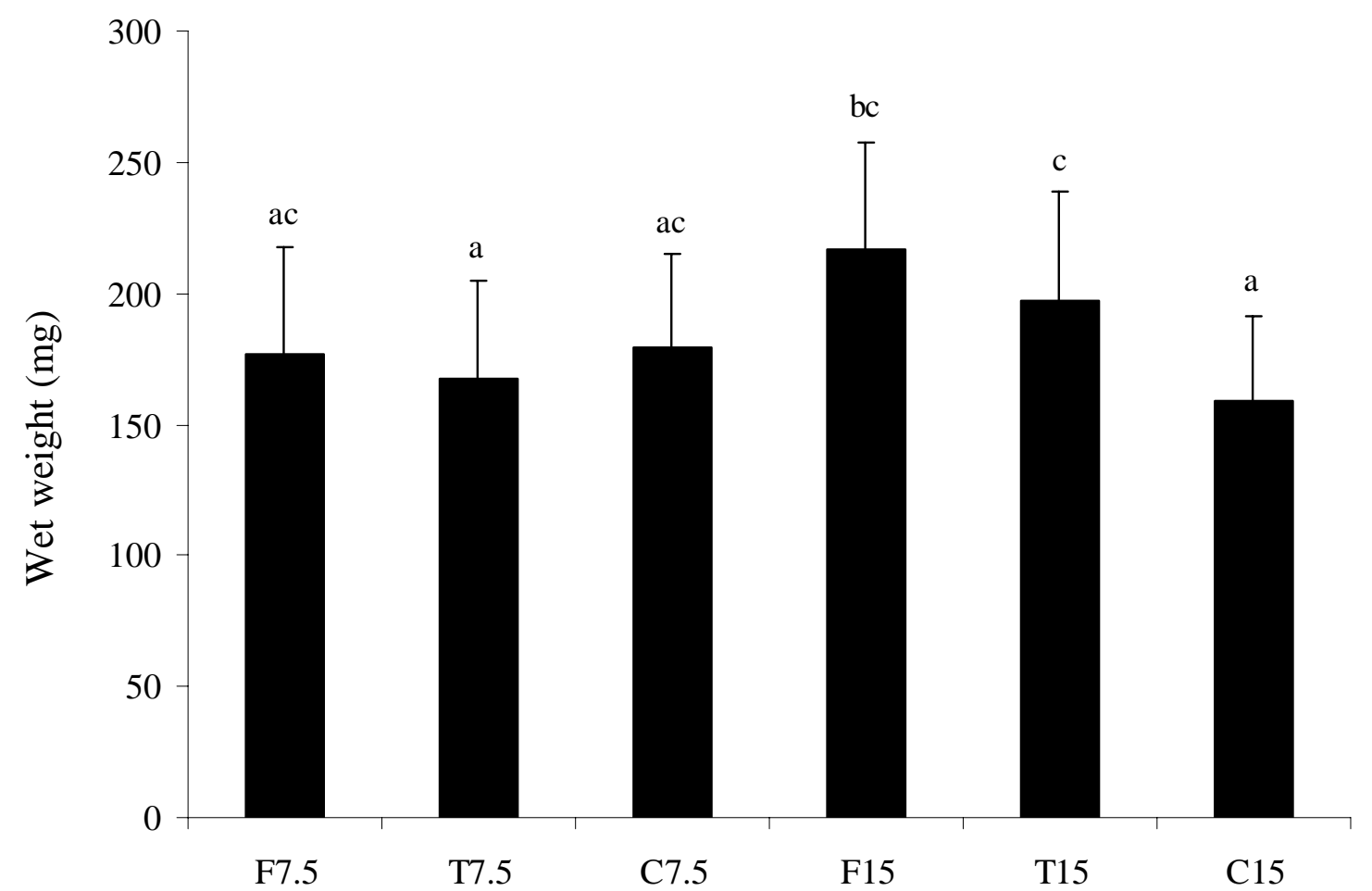

FIG. 2 

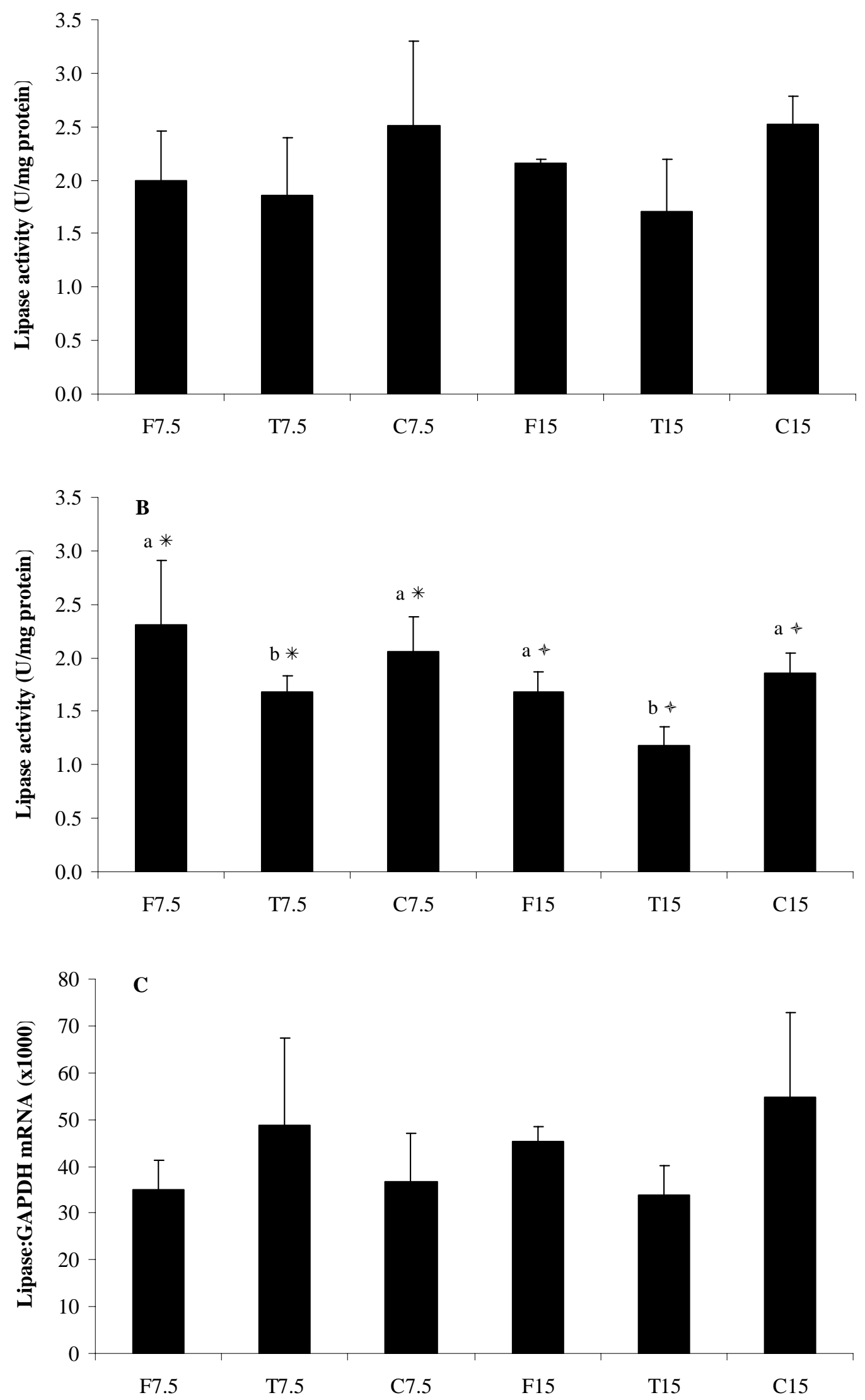

FIG. 3 

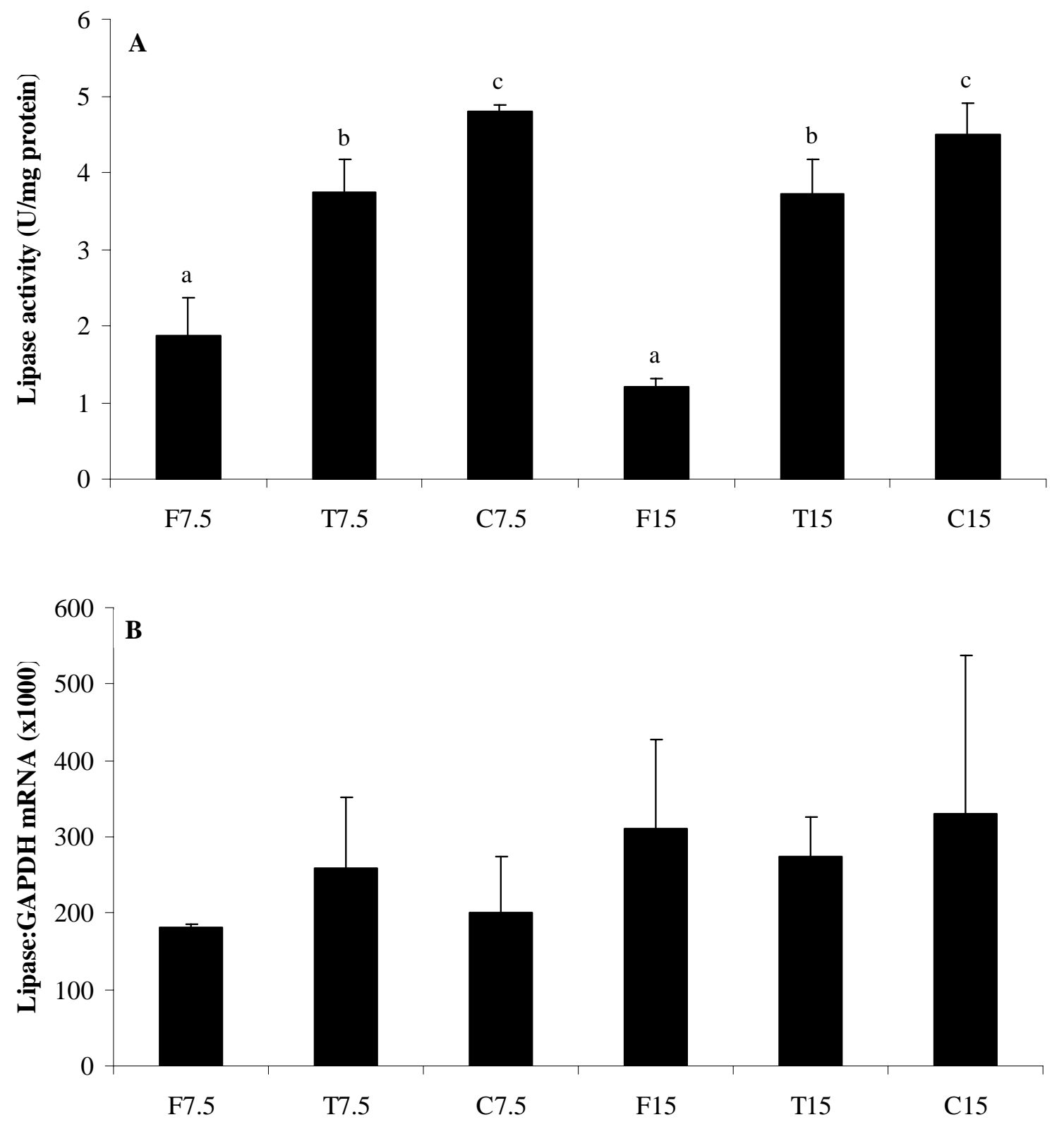

FIG. 4 